\title{
Estrutura de propriedade e criação de valor em companhias brasileiras
}

\author{
Ownership structure and value creation in Brazilian companies
}

\section{Elenice de Lourdes Corrêa}

Faculdade Novos Horizontes (FNH), Departamento de Administração, Programa de Pós-graduação em Administração, CEP: 30.180-121, Belo Horizonte, Minas Gerais, Brasil, elenicecorrea@hotmail.com

\section{Wendel Alex Castro Silva}

Faculdade Novos Horizontes (FNH), Departamento de Administração, Programa de Pós-graduação em Administração, CEP: 30.180-121, Belo Horizonte, Minas Gerais, Brasil, wendel.silva@unihorizontes.br

\section{Juliano Lima Pinheiro}

Faculdade Novos Horizontes (FNH), Departamento de Administração, Programa de Pós-graduação em Administração, CEP: 30.180-121, Belo Horizonte, Minas Gerais, Brasil, jlp@gold.com.br

\section{Alfredo Alves de Oliveira Melo}

Faculdade Novos Horizontes (FNH), Departamento de Administração, Programa de Pós-graduação em Administração, CEP: 30.180-121, Belo Horizonte, Minas Gerais, Brasil, sec-diretoria@unihorizontes.br

\section{Resumo}

O objetivo foi verificar se a estrutura de propriedade influencia na criação de valor e no risco das empresas brasileiras de capital aberto, entre 2005 e 2011, além de analisar os reflexos da crise de 2008 na estrutura dessas empresas. Os dados são secundários e trimestrais, do tipo série temporal e de corte (cross-section). É descritivo e quantitativo. Identificou-se uma tendência de queda nas concentrações de controle e de propriedade total. A estrutura de propriedade influenciou na criação de valor das empresas, mas não repercutiu no desempenho. Influenciou também a estrutura de capital, bem como o risco, o qual acarretou efeitos na criação de valor. Já o desempenho influenciou positivamente na criação de valor, visualizado pelo $Q$ de Tobin. As variações, tendências e características das medidas de desempenho, risco e criação de valor, observadas nos períodos próximos ao da ocorrência da crise financeira global de 2008, são indícios de que essas variáveis tenham sido afetadas pela crise.

Palavras-chave: Estrutura de propriedade, criação de valor, risco, teoria da agência, governança corporativa.

\begin{abstract}
The purpose of this investigation was to check if the ownership structure influenced the value creation, the economic performance and the risk of Brazilian companies between 2005 and 2011, considering the possible impacts of the global financial Crisis of 2008 on them. The research is descriptive-empirical, quantitative, and used the multiple regression method. An upward trend on the control and total ownership concentrations was verified. The ownership structure influenced the value creation, but did not reflect in the performance. Performance, capital structure and risk affected the value creation. The performance had a positive influence on value creation, noticed in Tobin's $Q$. Variations, trends and characteristics of performance measures, risk and value creation, observed in the periods near the occurrence of the Crisis of 2008 are evidence that these variables were affected by the Crisis.
\end{abstract}

Keywords: Ownership structure, value creation, risk, agency theory, corporate governance.

\section{Introdução}

A ocorrência de escândalos financeiros em corporações nos Estados Unidos, Itália e Reino Unido, nos anos 80 e 90, como os casos da Enron e WorldCom no início do ano 2000, alertou para a necessidade de adoção de medidas de controle e transparência das empresas. Foi a partir desses acontecimentos que se intensificou, nas grandes empresas, a busca pela implementação de boas práticas de governança corporativa (Oliveira, Oliveira, Forte, Ponte \& Geleilat, 2011).

A discussão existe desde o debate sobre a separação entre propriedade e controle nas empresas de capital aberto, assunto introduzido por Berle e Means (1932), e retomado por Jensen e Meckling em 1976 com a Teoria da Agência, pautada na relação entre acionista e administrador como uma relação de agência. E perceberam o aparecimento de divergências de interesse, o que definiram como problemas de agência. A separação entre propriedade e controle foi a principal causa dos problemas de agência. Esse tipo foi observado em empresas cuja estrutura de propriedade é pulverizada, mas La Porta, Lopez-de-Silanes, Shleifer e Vishny (1998) identificaram outro enfoque do conflito nas estruturas de propriedades concentradas. Nelas os conflitos acontecem entre acionistas controladores e minoritários, devido à possibilidade dos acionistas majoritários expropriarem os acionistas minoritários.

As medidas para solucionar esses conflitos são da esfera da governança corporativa. No Brasil, a adoção de práticas de governança foi intensificada a partir da última década, estimulada pela abertura da economia no país. Medidas legais e institucionais foram tomadas: a reestruturação da Lei das Sociedades por Ações por meio da Lei 10.303/2001, a criação do código de boas práticas de governança pelo Instituto Brasileiro de Governança Corporativa (IBGC), as recomendações da Comissão de Valores Mobiliários (CVM) e a criação dos níveis diferenciados de governança pela Bolsa de Valores de São Paulo (Bovespa) (Menezes, 2009; Melega, 2011). 
Entre as práticas ou mecanismos instituídos pela governança, tem-se a estrutura de propriedade utilizada como um mecanismo interno de proteção, cuja finalidade é alinhar os interesses dos gestores aos objetivos dos administradores por meio da posse de ações concedida aos gestores (Melega, 2011).

Em 2008, o mundo presenciou uma crise desencadeada nos EUA que provocou sérias restrições à liquidez em instituições bancárias e instabilidade nas bolsas de valores no mundo. A crise atingiu pode ter repercutido também na estrutura de propriedade das empresas brasileiras.

Os estudos têm buscado verificar a influência da estrutura de propriedade na criação de valor e no desempenho financeiro das empresas (Okimura, 2003; Okimura, Silveira \& Rocha, 2007; Dami, Rogers, Ribeiro \& Sousa, 2006; Menezes, 2009; Srivastava, 2011; Reyna, Vázquez \& Valdéz, 2012; Liu, 2013; Pinto \& Augusto, 2014) ainda não apresentaram um consenso nas conclusões a respeito da relação entre essas variáveis. Algumas constatam que inexiste relação significante, outras apontam relações positivas. Novos estudos já indicaram a possibilidade de uma influência parcial da estrutura de propriedade na criação de valor (Saito \& Silveira, 2008) e no desempenho (Okimura et al., 2007; Saito \& Silveira, 2008), o que instiga os pesquisadores para novos testes. Menezes (2009) apontou para um aumento na percepção de valor pelo mercado em função da adoção de boas práticas de governança corporativa. Considerando a não homogeneidade dos resultados, as discussões sobre o assunto permanecem inconclusivas. Ainda assim, o assunto tem sido pouco explorado no Brasil.

Assim, as perguntas norteadoras foram: i) A estrutura de propriedade influencia a criação de valor de companhias brasileiras de capital aberto listadas na Bovespa? ii) A estrutura de propriedade influencia o risco nas companhias brasileiras de capital aberto listadas na Bovespa?

O objetivo foi verificar se a estrutura de propriedade influencia na criação de valor e no risco das empresas brasileiras de capital aberto, entre 2005 e 2011, além de analisar os reflexos da crise de 2008 na estrutura dessas empresas.

\section{Referencial Teórico}

\subsection{Teoria da agência}

0 estudo de Jensen e Meckling (1976) é considerado um marco introdutório das pesquisas em governança corporativa, a partir do qual outros estudos se desenvolveram com abordagens diversas e complementares.

O problema de agência existe quando os interesses do agente e do principal estão desalinhados. A separação entre propriedade e controle é a causa dos conflitos de agência e, sendo ambas, agente e principal (gestor e acionista), maximizadores de utilidade, há boas razões para acreditar que o agente não agirá sempre em função do melhor interesse do principal. Tal argumentação pode ser entendida com base em outro estudo de Jensen e Meckling (1994) sobre os aspectos da natureza do comportamento humano. Ressaltaram as diferenças e interesses individuais e que as pessoas estão dispostas a fazer a melhor combinação que resulte em vantagens para si.

Para limitar as divergências, o acionista pode monitorar o gestor ou oferecer-lhe incentivos para alinhar seus interesses. Entretanto, os mecanismos para resolver o problema incorrem em custos para os acionistas, os custos de agência que, segundo Jensen e Meckling (1976), são formados pela soma dos gastos com: elaboração dos contratos entre o principal e o agente; ações de monitoramento das atividades dos agentes, como elaboração de relatórios, sistemas de informação e divulgação; e gastos realizados pelos próprios agentes para promover a transparência de informações entre ele e o principal e reduzir suas perdas residuais, isto é, a redução de riqueza.

\subsection{Governança Corporativa}

A governança corporativa teve origem justamente nas buscas de soluções para o problema de agência decorrente da separação entre propriedade e controle (Melega, 2011).

Para Shleifer e Vishny (1997), governança corporativa é o conjunto de restrições aplicadas sobre os gestores, por eles mesmos ou pelos investidores, buscando reduzir a alocação inadequada de recursos ex post e induzir os investidores a fornecerem mais recursos ex ante.

Dami et al. (2006) destacam que, em função da alta concentração de propriedade e do mercado de capitais pouco desenvolvido, no Brasil a questão central da governança é em torno do conflito de agência existente entre acionistas majoritários e minoritários. Para Carvalho (2002), tal situação indica uma mudança no paradigma, em que a boa governança adquire a finalidade de evitar que os acionistas controladores expropriem os interesses dos minoritários

Almeida, Almeida e Ness Jr. (2002) acrescentam que os conflitos de interesse não existem somente entre administradores e acionistas, eles ocorrem entre uma gama mais ampla de agentes (os stakeholders), isto é, entre acionistas majoritários e minoritários, credores, gerentes, empregados, consumidores, governo e a sociedade em geral. Nesse sentido, o desafio atual da governança corporativa é minimizar os conflitos entre todos esses agentes envolvidos, com objetivo de maximizar o valor da empresa e proporcionar um maior retorno para os acionistas.

Os mecanismos da governança corporativa são medidas de incentivo e controle que buscam alinhar os objetivos e harmonizar a relação entre acionistas e gestores, visando a redução dos conflitos de agência e, consequentemente, a minimização dos custos de agência. Esses mecanismos podem ser classificados como de proteção internos e externos. Os internos são: conselho administrativo, sistema de remuneração; estrutura de propriedade (posse de ações pelos gestores e conselheiros). Já os externos: mercado de aquisição hostil; mercado de trabalho competitivo e relatórios contábeis periódicos fiscalizados externamente (auditorias e agentes do mercado financeiro) (Silveira, 2002). 
Grande parte dos estudos exploram dois modelos de governança corporativa que sintetizam as características mais praticadas no mundo, o modelo anglo-saxão e o modelo nipo-germânico. 0 modelo nipo-germânico é comum no Japão, na Alemanha, na maior parte dos países da Europa Continental e no Brasil. Esse sistema é caracterizado por estruturas de propriedade concentradas, presença de grandes investidores e participações acionárias de longo prazo. (Okimura, 2003). Outra característica do sistema é a busca pelo equilíbrio dos interesses dos acionistas e dos grupos afetados pelas decisões da empresa, entre os quais estão os empregados, os clientes, os fornecedores e a comunidade em geral, isto é, os stakeholders (Carvalhal-da-Silva, 2002).

\subsection{Estrutura de Propriedade}

A estrutura de propriedade das empresas se difere quanto ao nível de concentração acionária, podendo este ser mais disperso ou mais concentrado, e quanto ao nível de controle. Naquelas mais dispersas, a propriedade das ações é pulverizada e há um grande número de acionistas. Nas concentradas, há poucos acionistas detendo grande quantidade de ações, existindo ainda o acionista controlador, aquele que detém o controle da empresa (Valadares, 1998).

No Brasil, o perfil das empresas de capital aberto é caracterizado pela alta concentração de propriedade, a presença de grandes investidores, inclusive estruturas familiares, que costumam monitorar a gestão, e pouca participação de fundos (de pensão e de investimento). É comum a emissão de duas categorias de ações: com direito e sem direito a voto (Valadares, 1998; Silveira, 2004). Dami et al. (2006), investigando as causas e consequências da estrutura de propriedade nas empresas brasileiras no ano de 2001, encontraram alta concentração de votos dos acionistas controladores com média de aproximadamente $60 \%$. Os três principais acionistas possuíam cerca $81 \%$ dos votos, confirmando achados de Leal, Carvalhal, Aloy Jr. e Lapagesse (2000) e de Carvalhal-da-Silva (2004), que apontaram que, de maneira geral, as empresas de capital aberto brasileiras são controladas em média pelos três principais acionistas. Entre possíveis causas da estrutura de propriedade presente no Brasil, os autores indicam a regulação do mercado, o tamanho da empresa e a instabilidade do mercado, sendo a regulação do mercado o principal determinante.

Okimura et al. (2007) encontraram nessas empresas uma média alta da concentração de votos dos acionistas controladores (média geral 76,1\%) e consideraram comparativamente baixa a concentração de propriedade do capital social total pelos controladores (média geral 53,7\%), entretanto, superior à metade do capital total das empresas. Segundo Silveira (2004), o perfil das empresas brasileiras caracterizado por alta concentração de propriedade e controle, em parte, pode ser explicado pelos incentivos que no passado eram dados para abertura de capital das empresas, que trouxe, ao mercado de ações, empresas que, na ausência de tais incentivos, provavelmente teriam sido mantidas privadas e controladas por poucos indivíduos.

\subsection{Criação de valor}

0 objetivo da empresa previsto na teoria das finanças corporativas é maximizar o valor da empresa, que, na prática, se restringe à maximização do valor para o acionista e do preço das ações, processo que se dá a partir das decisões de investimento, financiamento e das políticas de dividendos (Damodaran, 2004). As decisões de investimento implicam em onde aplicar ou alocar recursos para gerar valor e maximizar a riqueza; as decisões de financiamento tratam da escolha da fonte de recursos para se financiar; e a política de dividendos diz respeito às decisões sobre o destino dos lucros (Assaf Neto, 2010).

O nível de investimento esperado, segundo Lucchesi e Famá (2007), é um dos fatores que explicitamente acrescentam valor à empresa. Os acionistas esperam que a empresa gere retorno superior ao custo dos recursos investidos, promovendo uma valorização em seu valor de mercado (Assaf Neto, 2010). Por sua vez, os dirigentes procuram maximizar o valor da empresa ao tomar suas decisões de investimento (Lucchesi \& Famá, 2007).

Uma das maneiras de verificar a criação de valor, de acordo com Antunes e Procianoy (2003), é por meio da análise do valor das ações. Variações no preço das ações podem ocorrer como reflexo de informações transmitidas pelas empresas nos seus demonstrativos financeiros ou como reflexo das decisões de investimento. Isso ocorre porque o mercado distingue entre bons e maus investimentos e responde com reações negativas ou positivas às decisões de investimentos divulgadas pelas empresas (Chan, Gau \& Wang, 1995).

Para Araújo, Camargos e Castro Silva (2013), a criação de valor de companhias brasileiras, em anos recentes, pode ter sofrido influência do crescimento da economia do país.

\subsection{Risco}

Conforme Assaf Neto (2010), o conceito de risco está associado à possibilidade de ocorrência de um evento indesejável em relação a um valor esperado. 0 risco é um fator inerente a toda e qualquer atividade dos agentes econômicos, sobretudo, aos investidores e às empresas (Melo, 1997). 0 risco é um fator inerente a toda e qualquer atividade dos agentes econômicos, sobretudo, aos investidores e às empresas (Melo, 1997).

Segundo a abordagem tradicional, sob a perspectiva do empreendimento individual, o risco total da empresa pode ser dividido em risco financeiro e risco operacional, associados às decisões de financiamento e de investimento (Melo, 1997). 0 risco financeiro implica na possibilidade de insolvência da empresa, na incapacidade de cobrir gastos financeiros, e entre os fatores que o aumentam, destacamse: o endividamento, a volatilidade das vendas e dos custos, a concorrência agressiva, a falta de liquidez, a incapacidade administrativa e outros (Leite, 1994; Melo, 1997; Sanvicente, 2012 ). 0 risco operacional ou risco dos ativos (Sanvicente, 2012) está associado a um conjunto de riscos de macro variáveis que podem ameaçar as estratégias da empresa, expressando também o risco econômico. A incerteza sobre os fluxos de caixa futuros, em função das variabilidades das receitas e do impacto dos encargos 
financeiros das dívidas, expressa o risco econômico ou operacional. 0 beta do CAPM é admitido como medida padrão apropriada para mensurar o risco sistemático dos ativos (Tomazoni \& Menezes, 2002).

\section{Metodologia}

Trata-se de uma pesquisa descritiva e quantitativa (Cooper \& Schindler, 2011).

Os dados são secundários (Gujarati, 2000) coletados na Economática. A população compreendeu as companhias de capital aberto com ações listadas na Bovespa. A amostra é não probabilística (Cooper \& Schindler, 2011).

Os dados são de 2005 à 2011, trimestrais. Os valores foram ajustados por inflação com base no IPCA/IBGE acumulado de 31/12/2011. A amostra inicial compreendia 825 empresas, sendo expurgadas aquelas do setor de Finanças e Seguros, e aquelas com liquidez menor ou igual a $0,001 \%$. A distribuição da amostra final foi: Energia Elétrica (9,4\%); Construção $(8,4 \%)$ e Telecomunicações $(7,1 \%)$. Só $0,7 \%$ foram do setor de Papel e Celulose; 17,5\% foram de Outros Setores e 12,1\% não apresentaram classificação.

\subsection{Variáveis de estudo}

As variáveis foram escolhidas com base em trabalhos anteriores e relacionam-se às seguintes categorias: estrutura de propriedade, nível de controle, valor e desempenho (Okimura, 2003; Okimura et al., 2007; Iquiapaza, Gruberger \& Santos, 2007; Dami et al., 2006; Menezes, 2009; Caixe, 2012; Baptista, Matias \& Valle, 2013) e medidas de risco (Melo, 1997; Iquiapaza, Gruberger \& Santos, 2007; Lameira, Ness Jr., Motta \& Klotze, 2008).

A variável dependente foi criação de valor, medida pelo Q de Tobin (versão Chung \& Pruitt, 1994) e pelo valor da empresa em relação ao ativo total (VEAT)

As variáveis independentes foram representadas pelas medidas da estrutura de propriedade, desempenho e risco.

A estrutura de propriedade foi caracterizada pelas variáveis: concentração de controle (C.ORD); concentração de ações preferenciais (C.PREF); concentração de propriedade total (C.TOT) e excesso do direito de votos (EXC) (Cronqvist \& Nilsson, 2003).

As variáveis de desempenho foram: o lucro operacional dividido pelo ativo total (LOAT) e a margem EBITDA Earning Before Interest, Taxes, Depreciation and Amortization, (Salotti \& Yamamoto, 2005).

Os indicadores de risco foram: o índice de estrutura de Capital (ESTCAP); grau de endividamento (GA); a variabilidade da receita (VAR REC) e o beta $(\beta)$.
As variáveis de controle foram o tamanho da empresa (TAM) e a liquidez das ações em bolsa (LIQ).

A proposta do modelo consiste em testar: se a estrutura de propriedade influencia na criação de valor; se a estrutura de propriedade influencia no desempenho; se a estrutura de propriedade influencia no risco; se o desempenho influencia na criação de valor; se o risco influencia na criação de valor; se a estrutura de propriedade influencia indiretamente na criação de valor. Espera-se que, quanto mais concentrada a estrutura, menor a criação de valor; quanto maior o risco, menor a criação de valor; e quanto maior o desempenho, maior a criação de valor.

\subsection{Hipóteses do estudo}

As hipóteses foram definidas para análise das relações entre estrutura de propriedade e criação de valor $\left(\mathrm{H}_{\mathrm{a}}\right)$, entre estrutura de propriedade e desempenho $\left(\mathrm{H}_{\mathrm{b}}\right)$ e entre estrutura de propriedade e risco $\left(\mathrm{H}_{\mathrm{c}}\right)$, quais sejam:

Hoa $_{0}$ (nula): a estrutura não influencia na criação de valor das empresas; $\mathrm{H}_{1 \mathrm{a}}$ (alternativa): a estrutura influencia na criação de valor das empresas.

Hob (nula): a estrutura não influencia no desempenho das empresas; $\mathrm{H}_{1}$ b (alternativa): a estrutura influencia no desempenho das empresas; $\mathrm{H}_{2 \mathrm{~b}}$ (alternativa): o desempenho das empresas influencia na criação de valor; $\mathrm{H}_{3 \mathrm{~b}}$ (alternativa): no caso em que a estrutura influencia no desempenho das empresas, existe influência indireta com a criação de valor.

Hoc (nula): a estrutura não influencia o risco; $\mathrm{H}_{1 \mathrm{c}}$ (alternativa): a estrutura influencia o risco; $\mathrm{H}_{2 c}$ (alternativa): no caso em que a estrutura influencia o risco, nas estruturas mais dispersas o risco é menor; $\mathrm{H}_{3 \mathrm{~b}}$ (alternativa): o risco influencia na criação de valor das empresas; $\mathrm{H}_{4 c}$ (alternativa): no caso em que a estrutura influencia o risco, existe uma influência indireta com a criação de valor.

Os dados foram submetidos aos testes via software Statistical Package for the Social Science versão 16.0. A análise de regressão linear foi utilizada, além das análises de resíduos e outliers (Hair Jr., Black, Babin, Anderson \& Tatham, 2009), para avaliar a normalidade, homogeneidade e independência dos mesmos. Utilizou-se o nível de significância de $5 \%$.

\section{Apresentação e Análise dos Dados}

A Tabela 1 apresenta os resultados descritivos das variáveis investigadas. 
Tabela 1 - Resultado das variáveis estudadas

\begin{tabular}{|c|c|c|c|c|}
\hline Grupo & Variável & Média & $\begin{array}{l}\text { Desvio } \\
\text { Padrão }\end{array}$ & Características Observadas \\
\hline \multirow{5}{*}{$\begin{array}{l}\text { Estrutura de } \\
\text { propriedade }\end{array}$} & Concentração de controle & $43,20 \%$ & $24,80 \%$ & Tendência de queda \\
\hline & $\begin{array}{l}\text { Concentração de ações } \\
\text { preferenciais }\end{array}$ & $32,30 \%$ & $26,90 \%$ & $\begin{array}{l}\text { Dispersão e tendência de } \\
\text { queda no período }\end{array}$ \\
\hline & $\begin{array}{l}\text { Concentração de propriedade } \\
\text { total }\end{array}$ & $38,30 \%$ & $23,00 \%$ & Tendência de queda \\
\hline & Excesso de votos do controlador & 0,10 & 0,40 & Tendência de queda \\
\hline & $\begin{array}{l}\begin{array}{l}\text { Segundo e terceiro maiores } \\
\text { acionistas }\end{array} \\
\end{array}$ & $19,90 \%$ & $10,70 \%$ & Tendência de queda \\
\hline \multirow{2}{*}{ Desempenho } & $\begin{array}{l}\text { Lucro operacional em relação ao } \\
\text { Ativo Total }\end{array}$ & 0,015 & 0,069 & Grande instabilidade \\
\hline & Margem EBITDA & 0,032 & 0,04 & Tendência de queda \\
\hline \multirow{4}{*}{ Risco } & Estrutura de Capital & 0,214 & 3,269 & 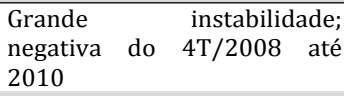 \\
\hline & Grau de Endividamento & 74,6 & 215,2 & $\begin{array}{l}\text { Tendência de crescimento a } \\
\text { partir do } 4 \mathrm{~T} / 2008\end{array}$ \\
\hline & Variabilidade das Receitas & 1,1 & 0,513 & Estabilidade \\
\hline & Beta & 0,749 & 0,451 & $\begin{array}{l}\text { Leve tendência de } \\
\text { crescimento; risco inferior ao } \\
\text { risco de mercado }\end{array}$ \\
\hline \multirow{2}{*}{$\begin{array}{l}\text { Criação de } \\
\text { valor }\end{array}$} & Q de Tobin & 1,835 & 7,172 & $\begin{array}{l}\text { Instabilidade; tendência de } \\
\text { crescimento }\end{array}$ \\
\hline & $\begin{array}{l}\text { Valor da Empresa em relação ao } \\
\text { Ativo Total }\end{array}$ & 1,56 & 4,261 & $\begin{array}{l}\text { Grande variabilidade; leve } \\
\text { tendência de crescimento }\end{array}$ \\
\hline \multirow[t]{2}{*}{ Controle } & Tamanho da empresa & $\begin{array}{c}\mathrm{R} \$ 2,5 \\
\text { milhões } \\
(\exp [14,7])\end{array}$ & $\begin{array}{l}\mathrm{R} \$ 1,8 \\
\text { milhões } \\
(\exp [14,4])\end{array}$ & $\begin{array}{l}\text { Queda em 2009; tendência de } \\
\text { crescimento }\end{array}$ \\
\hline & Liquidez & 0,183 & 0,395 & $\begin{array}{l}\text { Queda em 2008; tendência de } \\
\text { crescimento }\end{array}$ \\
\hline
\end{tabular}

Fonte: Elaboração própria.

Tabela 2 - Resumo dos resultados a partir das hipóteses

\begin{tabular}{|c|c|c|c|c|}
\hline Hipótese & Relação Avaliada & Decisão & Associações & $\begin{array}{l}\text { P-valor } \\
\text { (Significância) }\end{array}$ \\
\hline$H_{1 a}$ & $\begin{array}{l}\text { A estrutura de propriedade influencia na } \\
\text { criação de valor das empresas. }\end{array}$ & Não Rejeita & $\begin{array}{c}<\text { C.PREF > Q } \\
>\text { C.TOT }>\text { Q } \\
>\text { C.TOT > VEAT } \\
>\text { EXC > VEAT }\end{array}$ & $\begin{array}{l}0,037 \\
0,002 \\
0,002 \\
0,023\end{array}$ \\
\hline$H_{1 b}$ & $\begin{array}{l}\text { A estrutura de propriedade influencia no } \\
\text { desempenho das empresas. }\end{array}$ & Rejeita & - & - \\
\hline $\mathrm{H}_{2 b}$ & $\begin{array}{l}\text { O desempenho das empresas influencia } \\
\text { na criação de valor. }\end{array}$ & Não Rejeita & $\begin{array}{c}<\text { LOAT }>\text { Q } \\
<\text { EBITDA }>\text { Q } \\
>\text { EBITDA }>\text { VEAT }\end{array}$ & $\begin{array}{l}<0,012 \\
<0,001 \\
<0,001\end{array}$ \\
\hline$H_{3 b}$ & $\begin{array}{l}\text { No caso em que a estrutura de } \\
\text { propriedade influencia no desempenho } \\
\text { das empresas, existe influência indireta } \\
\text { com a criação de valor. }\end{array}$ & Rejeita & - & - \\
\hline$H_{1 c}$ & $\begin{array}{l}\text { A estrutura de propriedade influencia o } \\
\text { risco. }\end{array}$ & Não Rejeita & $>$ C.PREF $>$ ESTCAP & 0,002 \\
\hline$H_{2 c}$ & $\begin{array}{l}\text { No caso em que a estrutura de } \\
\text { propriedade influencia o risco, nas } \\
\text { estruturas mais dispersas o risco é } \\
\text { menor. }\end{array}$ & Não Rejeita & > C.PREF > ESTCAP & 0,002 \\
\hline$H_{3 c}$ & $\begin{array}{l}\text { O risco influencia na criação de valor das } \\
\text { empresas }\end{array}$ & Não Rejeita & $\begin{array}{l}<\text { ESTCAP }>\text { Q } \\
>\text { GA }>\text { VEAT }\end{array}$ & $\begin{array}{c}<0,001 \\
0,02\end{array}$ \\
\hline$H_{4 c}$ & $\begin{array}{l}\text { No caso em que a estrutura de } \\
\text { propriedade influencia o risco, existe } \\
\text { uma influência indireta com a criação de } \\
\text { valor. }\end{array}$ & Não Rejeita & $\begin{array}{c}>\text { C.PREF }>\text { ESTCAP } \\
\quad<\text { ESTCAP }>\text { Q } \\
\quad>\text { GA }>\text { VEAT }\end{array}$ & $\begin{array}{c}0,002 \\
<0,001 \\
0,02\end{array}$ \\
\hline
\end{tabular}

Fonte: Elaboração própria.

Para todos os modelos construídos, a avaliação da normalidade dos resíduos mostrou que estes seguem uma distribuição aproximadamente normal com variância constante em torno da média 0 e são independentes.
Portanto, pode-se considerar que as conclusões obtidas para o modelo de regressão são válidas.

0 resultado de todos os indicadores de estrutura de propriedade apresentaram tendência de decrescimento no 
período, distinto das evidenciadas de estudos anteriores (Silveira, 2002; Okimura, 2003; Okimura et al., 2007; Dalmacio \& Corrar, 2007; Dami et al., 2006) que analisaram de 1998 até 2005 e encontraram estruturas bem mais concentradas. Menezes (2009) já havia identificado redução a partir de 2003. Tais resultados demonstram que o perfil atual da estrutura está ficando mais disperso. Além de fatos, como o fortalecimento das práticas de governança e as mudanças introduzidas pela Lei das SAs, na década de 2000, há indícios de que os efeitos da crise econômica de 2008 tenham influenciado essa queda da concentração de propriedade.

As variáveis de desempenho, apresentaram queda no período, principalmente do $4 \mathrm{~T} / 2008$ até o $1 \mathrm{~T} / 2009$, o que provavelmente tenha sido reflexo da crise.

Entre as variáveis de risco, a estrutura de capital apresentou grande instabilidade e queda brusca do 4T/2008 ao 3T/2010. 0 grau de endividamento apresentou tendência de crescimento, com maior aumento a partir do 4T/2008. Apesar do elevado grau de endividamento, a variabilidade de receita apresentou estabilidade e manteve crescimento. 0 beta indicou ações com comportamento defensivo com riscos inferiores à média de risco do mercado.

As variáveis de criação de valor apresentaram instabilidade e tendência de crescimento. Em 2008 os índices apresentaram queda, principalmente, a partir do 3T. Tais resultados são indícios de provável reflexo da crise, mas, ainda assim, indicam que as empresas têm criado valor, e superiores aos resultados de Menezes (2009) e Caixe (2012). O tamanho e a liquidez apresentaram grande variabilidade e tendência de crescimento.

Os resultados evidenciaram que a estrutura influencia a criação de valor, sendo que, quanto menor a concentração de ações preferenciais, e quanto maior a concentração de propriedade total, maior o valor do Q de Tobin. E quanto maior a concentração de propriedade total e o excesso de votos do acionista controlador, maior o valor da empresa em relação ao ativo total. 0 resultado das relações entre estrutura de propriedade e criação de valor foi semelhante aos resultados de Menezes (2009) para a concentração de ações preferenciais, e contrário para o excesso de voto, que foi negativo, mesma relação encontrada por Okimura et al. (2007).

As variáveis de estrutura de propriedade, bem como as variáveis de controle, não apresentaram influência significativa com as variáveis de desempenho. Em estudos anteriores, Okimura et al. (2007) e Menezes (2009) identificaram relações positivas entre essas variáveis.

As variáveis de desempenho apresentaram associação significativa com o $Q$ de Tobin, demonstrando que o desempenho das empresas influencia na criação de valor. Entretanto, como a estrutura de propriedade não influencia no desempenho, indiretamente, não ela influencia na criação de valor

A concentração de ações preferenciais apresentou influência significativa na estrutura de capital das empresas, demonstrando que a estrutura de propriedade influencia o risco.

Foram encontradas associações significativas entre a estrutura de capital com o $\mathrm{Q}$ de Tobin e entre o grau de endividamento com o valor da empresa em relação ao ativo total, demonstrando que o risco influencia na criação de valor, inclusive indiretamente.

Quanto aos efeitos da crise na estrutura de propriedade das empresas, pressupõe-se que esta também tenha sido afetada pela crise. Uma das estratégias adotadas para diluir o risco em investimentos é a diversificação, ou seja, investir em diferentes ativos ou em ativos de diferentes setores (Brito \& Brito, 2002).Nesse sentido, embora sendo uma crise sistêmica, um dos reflexos da crise pode ter sido a busca pela diluição dos riscos, levando os acionistas a segregarem seus investimentos em diferentes empresas. Portanto, além da influência de fatores regulamentadores do mercado, a desconcentração de propriedade pode ter sido acentuada pela crise, sobretudo, no período de sua ocorrência, conforme se observa nos trimestres do ano de 2008.

\section{Considerações Finais}

0 objetivo geral foi verificar se a estrutura de propriedade influencia na criação de valor e no risco das empresas brasileiras de capital aberto, entre 2005 e 2011, além de analisar os reflexos da crise de 2008 na estrutura dessas empresas. Como variáveis independentes, consideraram-se estrutura de propriedade, risco e desempenho, e como variável dependente, a criação de valor, descrita segundo o $Q$ de Tobin, e o valor da empresa em relação ao ativo total. As características de controle foram o tamanho da empresa e a liquidez em bolsa.

Os indicadores de estrutura de propriedade apresentaram tendência de decrescimento no período analisado. Entre as variáveis de risco, a estrutura de capital apresentou grande instabilidade, o grau de endividamento revelou tendência de crescimento, principalmente, no $4 \mathrm{~T} / 2008$, o beta indicou tendência de crescimento e seu valor indicou ações com riscos inferiores aos do mercado. Apesar do alto grau de endividamento, a variabilidade de receita revelou estabilidade mantendo crescimento nos períodos. As variáveis de desempenho apresentaram queda. Os indicadores de criação de valor apresentaram instabilidade e tendência de crescimento. Em 2008 houve uma queda brusca a partir do 3T, como provável reflexo da crise. Mas, ainda assim, os índices indicam que as empresas têm criado valor. As variáveis tamanho e liquidez, apontaram variabilidade e tendência de crescimento.

A partir dos resultados das análises e dos testes das hipóteses, foi possível concluir que a estrutura de propriedade influencia a criação de valor no sentido de que, quanto menor a concentração de ações preferenciais e maior a concentração de propriedade total, maior será o valor do $Q$ de Tobin, e quanto maior a concentração de propriedade total e o excesso de votos do acionista controlador, maior o valor da empresa em relação ao ativo total. 
O desempenho das empresas também influencia na criação de valor em que, quanto menor o lucro operacional em relação ao ativo e quanto menor o EBITDA, maior será o Q de Tobin. Já o EBITDA influencia inversamente no valor da empresa em relação ao ativo total sendo que, quanto maior o EBITDA, maior será o valor da empresa em relação ao ativo total.

A estrutura de propriedade influencia o risco sendo que, quanto maior a concentração de ações preferenciais, maior será o índice de estrutura de capital das empresas - nas estruturas mais dispersas o risco é menor. 0 risco influencia na criação de valor para as empresas em que, quanto menor o índice de estrutura de capital, maior será o Q de Tobin e, quanto maior o grau de endividamento, maior o valor da empresa em relação ao ativo total.

Também se propôs analisar os reflexos da crise de 2008 na estrutura das empresas. Para isso, optou-se por analisar o período de 2005 a 2011, captando três anos antes e três anos depois da referida crise, além do período de sua ocorrência. A crise econômica mundial de 2008 é um tipo de risco sistêmico ou conjuntural. 0 risco sistêmico propaga-se a partir de uma instituição podendo atingir o sistema financeiro e as empresas no mundo inteiro. A crise sistêmica afeta o desempenho e os resultados das empresas. Os indicadores econômicos são todos impactados, devido ao risco de mercado a que as empresas ficam expostas.

Com base nos resultados, pode-se observar que os indicadores de risco, grau de endividamento e estrutura de capital foram os que mais evidenciaram possíveis efeitos da crise. Os indicadores de valor e desempenho também foram afetados, mas as empresas parecem ter reagido rapidamente à crise, recuperando os resultados em curto prazo.

E, houve sinais de que a crise de 2008 foi benéfica aos acionistas no sentido de incentivar a pulverização das estruturas de propriedade, reduzindo o risco dos papéis dessas companhias.

As modificações nas normas contábeis que alteraram a composição dos elementos das demonstrações contábeis e alguns critérios de contabilização não permitiram uma análise conjunta que captasse efeitos da crise econômica de 2008 e efeitos das convergências das normas contábeis. Além disso, faltaram dados em alguns períodos, os quais não foram imputados, pois, devido à grande variação apresentada, a média não faz efeito.

Como sugestão para trabalhos futuros, sugere-se comparar a evolução da concentração de propriedade no Brasil com outros mercados ou em empresas de diferentes setores, incluindo variáveis de governança corporativa e, ainda, analisar os reflexos dos novos critérios de contabilização nos indicadores de criação de valor, desempenho e risco após a convergência das normas contábeis no Brasil.

\section{Referências}

Almeida, F. G., Almeida, L. C., \& Ness Jr., W. L. (2002). A governança corporativa no setor de telecomunicações brasileiro. In Encontro Brasileiro de Finanças , 2, 2002, Rio de Janeiro. Anais do Encontro Brasileiro de Finanças, Rio de Janeiro: SBFIN.

Antunes, M. A., \& Procianoy, J. L. (2003). Os efeitos das decisões de investimento das empresas sobre os preços de suas ações no mercado de capitais. Revista de Administração de Empresas, São Paulo, 38(1), 5-14.

Araújo, E. A. T., Camargos, M. A., \& Castro Silva, W. A. (2013). Analysis of the effects of implement investments decisions on operational performance, profitability and value creation of Brazilian companies. Tourism \& Management Studies, 3(Special Issue), 762-777.

Assaf Neto, A. (2010). Finanças corporativas e valor (5⿳亠丷厂 ed.). São Paulo: Atlas.

Baptista, Celísia, Matias, Fernanda, \& Valle, Patrícia Oom do. (2013). The moderating role of strategy and environment on the relationship between corporate liquidity and investment: evidence from panel data. Tourism \& Management Studies, 9(1), 85-91.

Berle, A. A., \& Means, G. C. (1932). The modern corporation and private property. New York: Macmillan.

Brito, A. A., \& Brito, N. R. O. (2002). Diversificação de risco e choques exógenos sobre o mercado de capitais brasileiro. Revista de Administração de Empresas, 37(1), 19-28.

Caixe, D. F. (2012). Relação dinâmica entre a estrutura de propriedade e controle e o valor de mercado corporativo no Brasil: análise da primeira década do século XXI. Dissertação (Mestrado em Administração), Faculdade de Economia, Administração e Contabilidade da Universidade de São Paulo, São Paulo.

Carvalhal-da-Silva, A. L. (2002). A influência da estrutura de controle e propriedade no valor, estrutura de capital e política de dividendos das empresas brasileiras. Tese (Doutorado em Administração), Instituto COPPEAD de Administração, Universidade Federal do Rio de Janeiro, Rio de Janeiro.

Carvalhal-da-Silva, A. L. (2004). Governança corporativa, valor, alavancagem e política de dividendos das empresas brasileiras. Revista de Administração de Empresas, 39(4), 348-361.

Carvalho, A. G. (2002). Governança corporativa no Brasil em perspectiva. Revista de Administração de Empresas, 37(3), 19-32.

Chan, Su H., Gau, G. W., \& Wang, K. (1995). Stock market reaction to capital investment decisions: evidence from business relocations. Journal of Financial and Quantitative Analysis, 30(1), 81-100.

Chung, K., \& Pruitt, S. (1994). A simple approximation of Tobin's Q. Financial Management, 23(3), 70-74.

Cooper, D. R., \& Schindler, P. S. (2011). Métodos de pesquisa em administração (10 $\mathrm{a}$ ed.). Porto Alegre: Bookman.

Cronqvist, H., \& Nilsson, M. (2003). Agency costs of controlling minority shareholders. Journal of Financial and Quantitative Analysis, 38(4), 695-719.

Dalmacio, F. Z., \& Corrar, L. J. (2007). A concentração do controlo acionário e a política de dividendos das empresas listadas na Bovespa: uma abordagem exploratória à luz da teoria da agência. Revista de Contabilidade e Organizações, 1(1), 16-29.

Dami, A. B. T., Rogers, P., Ribeiro, K. C. S., \& Sousa, A. F. (2006). Governança corporativa e estrutura de propriedade no Brasil: causas e consequências. In Encontro Brasileiro de Finanças, 6, 2006, Vitória. Obtido a 22 de abril de 2012, em http://www.pablo.prof.ufu.br/artigos/ebf3.pdf.

Damodaran, A. (2004). Finanças corporativas: teoria e prática. Porto Alegre: Bookman.

Gujarati, D. N. (2000). Econometria básica (3ª ed.). São Paulo: Makron Books.

Hair Jr., J. F., Black, W.C., Babin, B. J., Anderson, R. E., \& Tatham, R. L. (2009). Análise multivariada de dados (6 $6^{\mathrm{a}}$ ed.). Porto Alegre: Bookman.

Instituto Brasileiro de Governança Corporativa (IBGC) (2012). Obtido a 29 setembro de 2012, em http://www.ibgc.org.br/Home.aspx.

Iquiapaza, R. A., Gruberger, D. J., \& Santos, I. T. (2007). A endogeneidade da estrutura de propriedade, governança corporativa e criação de valor na Bovespa no período 2002-2005. In Encontro da Associação Nacional de Pós-graduação e Pesquisa em Administração, 31, 2007, Rio de Janeiro (RJ). Anais do EnANPAD, Rio de Janeiro: ANPAD.

Jensen, M. C., \& Meckling, W. H. (1976). Theory of the firm: managerial behavior, agency costs and ownership structure. Journal of Financial Economics, 3(4), 305-360. 
Jensen, M C., \& Meckling, W. H. (1994). The nature of man. Journal of Applied Corporate Finance, 7(2), 4-19.

La Porta, R., Lopez-de-Silanes, F., Shleifer, A., \& Vishny, R. (1998). Law and finance. The Journal of Political Economy, 106(6), 11131155.

Lameira, V. J., Ness Jr., W. L., Motta, L. F. J., \& Klotzle, M. C. (2008). Como estrutura de propriedade, transparência, administração e relacionamento com investidores se relacionam com risco e desempenho das companhias abertas brasileiras. Revista de Administração Eletrônica (RAUSP-e), 1(2), 1-17.

Leal, R. P. C., Carvalhal, A., Aloy Jr., R., \& Lapagesse, G. (2000). Estrutura de controle e valor de mercado das empresas brasileiras. In Encontro da Associação Nacional dos Programas de Pósgraduação em Administração, 24, 2000, Florianópolis (SC). Anais do EnANPAD, Rio de Janeiro: ANPAD.

Lei Federal no 10.303 de 31 de outubro de 2001. Presidência da República do Brasil, Brasília. Obtido a 27 de janeiro de 2014, em: http://www.planalto.gov.br/ccivil_03/leis/LEIS_ 2001/L10303.htm.

Leite, H. P. (1994). Introdução à administração financeira (2aㅡ ed.). São Paulo: Atlas.

Liu, H. (2013). The relationship between ownership structure and corporate performance: an empirical study based on listed companies of Shenzhen Stock Exchange. Dissertação (Mestrado em Finanças). Saint Mary's University, Halifax, Nova Scotia.

Lucchesi, E. P., \& Famá, R. (2007). O impacto das decisões de investimento das empresas no valor de mercado das ações negociadas na Bovespa no período de 1996 a 2003. Revista de Administração de Empresas, 42(2), 249-260.

Melega, R. (2011). Desempenho da firma e práticas de governança corporativa: um modelo de equações simultâneas. Tese (Doutorado), Escola de Engenharia de São Carlos da Universidade de São Paulo, São Carlos.

Melo, A. A. O. (1997). O estudo da relação risco/retorno em empresas brasileiras: análise no período 1998/1995. Tese (Professor titular), Faculdade de Ciências Econômicas, Universidade Federal de Minas Gerais, Belo Horizonte.

Menezes, R. M. A. (2009). Estrutura de propriedade e a governança corporativa têm relação com o valor e desempenho das empresas no novo cenário de mercado de capitais brasileiro? Dissertação (Mestrado em Administração), Fundação Instituto Capixaba de Pesquisas em Contabilidade, Economia e Finanças (FUCAPE), Vitória.

Okimura, R. T. (2003). Estrutura de propriedade, governança corporativa, valor e desempenho das empresas no Brasil. Dissertação (Mestrado em Administração), Departamento de Administração da Faculdade de Economia, Administração e Contabilidade da Universidade de São Paulo, São Paulo.

Okimura, R. T., Silveira, A. D. M., \& Rocha, K. C. (2007). Estrutura de propriedade e desempenho corporativo no Brasil. Revista de Administração Contemporânea-Eletrônica, 1(1), 119-135.

Oliveira, O. V., Oliveira, M. C., Forte, S. H. A. C., Ponte, V. M. R., \& Geleilat, J. M. G. (2011). Barreiras à adoção de melhores práticas de governança corporativa. In Encontro de Estudos em Estratégia/3E, 5, 2011, Porto Alegre (RS). Anais do Encontro, Rio de Janeiro: ANPAD.

Pinto, A. P. S., Augusto, M. G. (2014). Are there non-linear relationships between ownership structure and operational performance? Empirical evidence from portuguese SMEs using dynamic panel data. International Journal of Business Administration, 5(3), 162-180.

Reyna, J. M. S. M., Vázquez, R. D., Valdés, A. L. (2012). Corporate governance, ownership structure and performance in Mexico. International Business Research, 5(11), 12-27.

Saito, R., \& Silveira, A. D. M. (2008). Governança corporativa: custos de agência e estrutura de propriedade. Revista de Administração de Empresas, São Paulo, 48(2), 79-86.

Salotti, B. M., \& Yamamoto, M. M. (2005). Um estudo empírico sobre o EBITDA como representação do fluxo de caixa operacional estudo em empresas brasileiras. In Congresso USP de Controladoria e Contabilidade, 5, 2005, São Paulo. Anais do Congresso, São Paulo: FEA/USP.
Sanvicente, A. Z. (2012). Problemas de estimação de custo de capital de empresas concessionárias no Brasil: uma aplicação à regulamentação de concessões rodoviárias. Revista de Administração de Empresas, 47(1), 81-95.

Shleifer, A., \& Vishny, R. W. (1997). A survey of corporate governance. Journal of Finance, 52(2), 737-783.

Silveira, A. D. M. (2002). Governança corporativa, desempenho e valor da empresa no Brasil. Dissertação (Mestrado em Administração), Faculdade de Economia, Administração e Contabilidade da Universidade de São Paulo, São Paulo.

Silveira, A. D. M. (2004). Governança corporativa e estrutura de propriedade: determinantes e relação com o desempenho no Brasil. Tese (Doutorado), Faculdade de Economia, Administração e Contabilidade da Universidade de São Paulo, São Paulo.

Srivastava, A. (2011). Ownership Structure and Corporate Performance: Evidence from India. International. Journal of Humanities and Social Science, 1(1), 23-29.

Tomazoni, T., \& Menezes, E. A. (2002). Estimativa do custo de capital de empresas brasileiras de capital fechado (sem comparáveis de capital aberto). Revista de Administração de Empresas, 37(4), 38-48.

Valadares, S. M. (1998). Três ensaios sobre mercado por controle no Brasil. Tese (Doutorado em Economia), Departamento de Economia da Pontifícia Universidade Católica do Rio de Janeiro, Rio de Janeiro.

Submetido: 30.05 .2014

Aceite: 26.11 .2014 